\title{
The optimal manufacturer's reserve
}

\section{investment and government's subsidy policy in emergency preparedness}

\section{Zili Zhang* and Xiangyang Li}

*Correspondence:

n705zzl@126.com

School of Management, Harbin

Institute of Technology, 92 West

Dazhi Street, Harbin, China

\section{空 Springer}

\begin{abstract}
Emergency supplies are of great importance when coping with a disaster. The stockpiling and production of emergency supplies should depend on private manufacturers in some cases, and the government will offer the manufacturer a subsidy to encourage its investment on extra reserves. This study investigates the manufacturer's optimal decision on reserve investment and the government's optimal subsidy policy based on mathematical models. The results indicate that to gain maximum benefit, the manufacturer should allocate its funds on both physical material reserve and production capacity reserve according to the government's subsidy policy, while the government should take note of the relation between subsidy policy and subsidy period to ensure the manufacturer's provision level of emergency supplies.
\end{abstract}

Keywords: emergencies; physical material reserves; production capacity reserves; subsidy policy

\section{Introduction}

Reserves of emergency goods and production capacity play an important role in disaster relief and mitigation. Yet, only the ability of the government is not enough to provide sufficient emergency supplies to numerous victims in a large-scale disaster or bioterrorism event. Some attempts have been made to involve private companies in emergency preparedness by making them aware that they have vested interests in the impact area through customers, suppliers, and corporate values of social responsibility. Nevertheless, a private company maintains a level of inventory on purpose of producing certain range of products and services. A humanitarian inventory often goes beyond the private sector's regular operation of producing in the most efficient and economical manner. Thus, the private business is unlikely to respond to the mobilization of emergency reserves if the government did not give them certain subsidies. In practice, the government usually negotiates a contract with related manufacturers on the emergency reserve schemes in terms of categories and quantities of items, price, subsidies, etc. However, little is known regarding the reasonable subsidy policy and manufacturers' optimal reserve investment in disaster preparedness. Therefore, this study addresses the following specific research questions by the application of inequalities in optimization:

(c) 2013 Zhang and Li; licensee Springer. This is an Open Access article distributed under the terms of the Creative Commons Attribution License (http://creativecommons.org/licenses/by/2.0), which permits unrestricted use, distribution, and reproduction in any medium, provided the original work is properly cited. 
(1) Given the government's subsidy policy for private emergency reserves of physical materials and production capacity, how should the manufacturer make the optimal investment decision?

(2) How should the government determine optimal subsidy policy in order to ensure the manufacturer's provision level of emergency supplies?

\section{Literature review}

Emergency preparedness is crucially important to eliminate or reduce the damage caused by disasters (Natarajarathinam et al. [1]). The emergency-management-related activities traditionally belong to the domain and responsibility of local, state, and federal governments (Lettieri et al. [2]; Wilson and Oyola-Yemaiel [3]). People around the world expect their governments to have resources to respond to disasters in a timely and effective fashion. However, numerous natural and man-made disasters over the past decade, such as hurricanes, terrorist attacks, tornadoes, floods, mudslides, and oil/chemical spills, have highlighted the challenge of crafting appropriate response capabilities and interagency procedures for even the most well-resourced nations (Hense et al. [4]). Moreover, in some cases, governmental entities failed in the emergency management function (Edwards [5]), resulting in the increased importance of corporations.

Corporations often occupy an important social space in the provision of resources, administrative efficiency, and contacts to address the effects of disasters (Johnson et al. [6]). Stewart et al. [7] believed that private sector companies can respond both efficiently and effectively to the needs of impacted areas and receiving communities. Actually, the federal government of the United States has recognized that the resources and skills that private corporations possess are needed in times of disaster (Johnson et al. [6]). Hence there is the need to involve private industry in the strategy to boost performance for disaster management (Fitzgerald [8]; Cohen [9]). In view of the current mandates by governments to improve the efficacy of disaster response and preparedness efforts, corporate involvement in disaster-related activities has become a topic for academic research (Johnson et al. [6]).

Chen and Huang [10] noted that government should utilize the power of society fully and establish a complete system of emergency relief reserves to meet the relief demands. Hutchison [11] has recommended partnerships between governments and the private sector in prevention, preparedness, response, and recovery efforts to reinvigorate local economics and their resilience toward future disasters. Giving the private sector as much freedom as possible to provide resources for relief and recovery efforts and ensure that its role is officially acknowledged as part of emergency protocols was suggested (Horwitz [12]).

However, current research in the domain of public-private partnerships does not adequately address the diversity of interaction that is needed to facilitate higher levels of resilience in the wake of a disaster (Stewart et al. [7]). When considering the fact that disasters can overwhelm governmental response efforts (Wise and Nader [13]; Edwards [14]), a more explicit understanding of what corporations do in the context of disasters may continue to grow in importance (Johnson et al. [6]). In emergency management systems, a private sector should have more opportunity and responsibility to provide resources for response and recovery operations (Unlu et al. [15]). Chen and Huang [10] indicated that the emergency supplies reserve strategy in the form of ex-ante government and enterprise co-reserve is superior to the strategy in the form of ex-post emergency procurement and emergency production with fund limitation and high social cost. 
Governments and manufacturers that produce batteries, generators, and other supplies and equipment needed in times of crises must determine appropriate stock levels to support a potential initial response operation (Lodree Jr. and Taskin [16]) since holding large amounts of inventory is impractical due to high demand uncertainty, highly variable production times, and high holding costs. In particular, a certain amount of spare production capacity should be reserved to meet continuous demand, once emergency demand exceeds on-hand inventory. Li et al. [17] indicated that production capacity reserve is useful for the resources whose ordinary consumption is small in peacetime but demand is large in emergency. Nevertheless, disasters are so uncertain that many manufacturers tend to underestimate emergency demand in order to gain more profits in peacetime. In other words, it is unreasonable for manufacturers to take the risks of profit loss by themselves without any incentive from the government while executing emergency reserves. Therefore, the current study will attempt to address this problem by designing a win-win strategy which can increase a relevant manufacturers' desire to participate in reserve work for emergency resources.

\section{Model description and analysis}

(1) In a next period $T$, the government will give subsidy to the manufacturer for its reserves of physical materials and production capacity in case of an emergency event. The government's subsidy policy is reflected by $\delta_{1}$ and $\delta_{2}$. The government will grant the manufacturer subsidies for a proportion $\left(\delta_{1}\right)$ in its total emergency reserve of physical materials and for a proportion $\left(\delta_{2}\right)$ in its total emergency reserve of production capacity.

(2) When $t=0$, the manufacturer plans to use certain capital (set to one for simplicity) to build up emergency reserves for physical materials and production capacity, and allocates the capital to physical material and production capacity reserve building in a rate of $\eta$ to $1-\eta(0<\eta<1) . W_{1}$ and $W_{2}$ denote the potential maximums of physical material and production capacity reserves. $\theta_{1} W_{1}$ and $\theta_{2} W_{2}$ denote the manufacturer's current (i.e., $t=0$ ) reserves of physical materials and production capacity.

(3) Let $x$ and $y$ be the manufacturer's reserves of physical materials and production capacity at time $t$, respectively. Due to the manufacturer's low reserve at $t=0$, we assume that the physical material and production capacity reserves increase in the period $T$, but the increase speed is declining over time. Thus, the increasing model of the manufacturer's reserves of physical materials and production capacity is

$$
\left\{\begin{array}{l}
d x / d t=\alpha \eta\left(W_{1}-x\right) \\
d y / d t=\beta(1-\eta)\left(W_{2}-y\right)
\end{array}\right.
$$

where $\alpha$ and $\beta$ denote the manufacturer's ability in building reserves of physical materials and production capacity, respectively.

(4) We assume $\delta_{1}, \delta_{2} \in(0,1), W_{1}<W_{2}, \alpha>\beta$, and $\theta_{1}>\theta_{2} . \delta_{1}, \delta_{2} \in(0,1)$ denotes that the government gives subsidies for a proportion out of the total emergency reserves of physical materials and production capacity. This is because if the government provides full subsidies, the manufacturer may limitlessly expand the reserves. $W_{1}<W_{2}$ shows that the manufacturer has more expandable room for production capacity. To meet the large number of orders as well as reduce storage, many manufacturers can have flexible standby machines capable of performing operation in addition to the main production line, thus the 
potential maximum of production capacity is supposed to be larger than that of physical material storage. $\alpha>\beta$ denotes that for a manufacturer the ability in building physical material reserve is higher than in building production capacity reserve. Finally, because the expandable room for production capacity is much bigger, we assume that the proportion of manufacturer's reserve of physical materials at $t=0$ in the potential maximum of physical material reserve is larger than the proportion of manufacturer's reserve of production capacity at $t=0$ in the potential maximum of production capacity reserve, namely, $\theta_{1}>\theta_{2}$.

\subsection{Manufacturer's optimal decision}

As $x-\theta_{1} W_{1}$ and $y-\theta_{2} W_{2}$ are the increase in a manufacturer's reserves of physical materials and production capacity at time $t$, and $\delta_{1}$ and $\delta_{2}$ are government subsidy on them, $\delta_{1}(x-$ $\left.\theta_{1} W_{1}\right)$ and $\delta_{2}\left(y-\theta_{2} W_{2}\right)$ are the benefit that a manufacturer gains from the emergency reserves of physical materials and production capacity. Therefore, the expected benefit the manufacturer obtains from the government subsidy in the next period $T$ is

$$
E(\eta)=\int_{0}^{T}\left[\delta_{1}\left(x-\theta_{1} W_{1}\right)+\delta_{2}\left(y-\theta_{2} W_{2}\right)\right] d t .
$$

The manufacturer needs to determine the investment rate $\eta$ for the two types of reserves in the hope of maximizing $E(\eta)$. According to the initial condition $(t=0)$, we solve Eq. (1) and obtain the following set of equalities:

$$
\left\{\begin{array}{l}
x=W_{1}+\left(\theta_{1}-1\right) W_{1} e^{-\alpha \eta t}, \\
y=W_{2}+\left(\theta_{2}-1\right) W_{2} e^{-\beta(1-\eta) t} .
\end{array}\right.
$$

By substituting these equalities into the objective function Eq. (2), we obtain

$$
\begin{aligned}
E(\eta)= & \int_{0}^{T}\left[\delta_{1} W_{1}\left(1-\theta_{1}\right)\left(1-e^{-\alpha \eta t}\right)+\delta_{2} W_{2}\left(1-\theta_{2}\right)\left(1-e^{-\beta(1-\eta) t}\right)\right] d t \\
= & {\left[\delta_{1} W_{1}\left(1-\theta_{1}\right)+\delta_{2} W_{2}\left(1-\theta_{2}\right)\right] T-\frac{\delta_{1} W_{1}\left(1-\theta_{1}\right)\left(1-e^{-\alpha \eta T}\right)}{\alpha \eta} } \\
& -\frac{\delta_{2} W_{2}\left(1-\theta_{2}\right)\left(1-e^{-\beta(1-\eta) T}\right)}{\beta(1-\eta)} .
\end{aligned}
$$

Proposition 1 If the subsidy period $T$ is long enough, for the government's any subsidy policy $\delta_{1} / \delta_{2}$, there is only one optimal decision $\eta^{*} \in(0,1)$, which makes the manufacturer's expected benefit $E(\eta)$ maximum. If the subsidy period $T$ is short, the government should select an appropriate subsidy policy $\delta_{1} / \delta_{2}$ to ensure that the manufacturer has the optimal decision $\eta^{*} \in(0,1)$.

Proof Let the subsidy policy of the government be $\delta_{1} / \delta_{2}$. Accordingly, the manufacturer decides $\eta \in(0,1)$ to maximize its expected benefit $E(\eta)$. Taking the derivative of Eq. (4), we have

$$
\begin{aligned}
\frac{\partial E(\eta)}{\partial \eta}= & -\frac{W_{1} \delta_{1}\left(1-\theta_{1}\right)}{\alpha} \cdot \frac{(\eta \alpha T+1) e^{-\alpha \eta T}-1}{\eta^{2}} \\
& +\frac{\delta_{2} W_{2}\left(1-\theta_{2}\right)}{\beta} \cdot \frac{[(1-\eta) \beta T+1] e^{-\beta(1-\eta) T}-1}{(1-\eta)^{2}} .
\end{aligned}
$$


When the manufacturer comes to its optimal decision, there exists $\eta^{*} \in(0,1)$ which makes $\partial E / \partial \eta^{*}=0$. Based on the zero-point theorem, if $\lim _{\eta \rightarrow 0^{+}} \partial E(\eta) / \partial \eta>0$ and $\lim _{\eta \rightarrow 1^{-}} \partial E(\eta) / \partial \eta<0, E(\eta)$ is sure to have an extreme value with $\eta \in(0,1)$

$$
\begin{aligned}
\lim _{\eta \rightarrow 0^{+}} \frac{\partial E(\eta)}{\partial \eta} & =\frac{W_{1} \delta_{1} \alpha T^{2}\left(1-\theta_{1}\right)}{2}-\frac{W_{2} \delta_{2}\left(1-\theta_{2}\right)}{\beta} \cdot \frac{e^{\beta T}-\beta T-1}{e^{\beta T}} \\
& >\frac{W_{1} \delta_{1} \alpha T^{2}\left(1-\theta_{1}\right)}{2}-\frac{W_{2} \delta_{2}\left(1-\theta_{2}\right)}{\beta}, \\
\lim _{\eta \rightarrow 1^{-}} \frac{\partial E(\eta)}{\partial \eta} & =\frac{W_{1} \delta_{1}\left(1-\theta_{1}\right)}{\alpha} \cdot \frac{e^{\alpha T}-\alpha T-1}{e^{\alpha T}}-\frac{\delta_{2} W_{2}\left(1-\theta_{2}\right)}{\beta} \cdot \frac{\beta^{2} T^{2}}{2} \\
& <\frac{W_{1} \delta_{1}\left(1-\theta_{1}\right)}{\alpha}-\frac{\delta_{2} W_{2}\left(1-\theta_{2}\right) \beta T^{2}}{2} .
\end{aligned}
$$

According to Eq. (6), if $\frac{W_{1}\left(1-\theta_{1}\right) \delta_{1} \alpha T^{2}}{2}-\frac{\left(1-\theta_{2}\right) \delta_{2} W_{2}}{\beta} \geq 0$, then $T_{1} \geq \sqrt{\frac{2 \delta_{2} W_{2}\left(1-\theta_{2}\right)}{W_{1} \delta_{1} \alpha \beta\left(1-\theta_{1}\right)}}$. According to Eq. (7), if $\frac{W_{1} \delta_{1}\left(1-\theta_{1}\right)}{\alpha}-\frac{\left(1-\theta_{2}\right) \delta_{2} W_{2} \beta T^{2}}{2} \leq 0$, then $T_{2} \geq \sqrt{\frac{2 W_{1} \delta_{1}\left(1-\theta_{1}\right)}{W_{2} \delta_{2} \alpha \beta\left(1-\theta_{2}\right)}}$. As a consequence, if $T_{1} \geq T_{2}$, we have

$$
\frac{\delta_{1}}{\delta_{2}} \leq \frac{W_{2}\left(1-\theta_{2}\right)}{W_{1}\left(1-\theta_{1}\right)} \quad \text { and } \quad T \geq T_{1} \geq \sqrt{\frac{2 \delta_{2} W_{2}\left(1-\theta_{2}\right)}{W_{1} \delta_{1} \alpha \beta\left(1-\theta_{1}\right)}}
$$

Otherwise, if $T_{1}<T_{2}$, we have

$$
\frac{\delta_{1}}{\delta_{2}}>\frac{W_{2}\left(1-\theta_{2}\right)}{W_{1}\left(1-\theta_{1}\right)} \quad \text { and } \quad T \geq T_{2} \geq \sqrt{\frac{2 W_{1} \delta_{1}\left(1-\theta_{1}\right)}{W_{2} \delta_{2} \alpha \beta\left(1-\theta_{2}\right)}} .
$$

The two conditions described by Eq. (8) and Eq. (9) can ensure that the manufacturer has the optimal decision.

When the subsidy period $T$ is fixed, if the government adjusts subsidy policy to make $\delta_{1} / \delta_{2}$ satisfy the following inequations, the manufacturer can also reach an optimal decision

$$
\frac{2 W_{2}\left(1-\theta_{2}\right)}{W_{1} \alpha \beta\left(1-\theta_{1}\right) T^{2}}<\frac{\delta_{1}}{\delta_{2}}<\frac{W_{2} \alpha \beta\left(1-\theta_{2}\right) T^{2}}{2 W_{1}\left(1-\theta_{1}\right)} \quad \text { and } \quad T>\sqrt{\frac{2}{\alpha \beta}} .
$$

According to Eq. (6) and Eq. (7), if the subsidy period T satisfies Eq. (8) and Eq. (9), or $\left(\delta_{1} / \delta_{2}, T\right)$ satisfies Eq. (10), then the following inequations are true:

$$
\begin{aligned}
& \lim _{\eta \rightarrow 0^{+}} \frac{\partial E}{\partial \eta}>\frac{W_{1} \delta_{1} \alpha T^{2}\left(1-\theta_{1}\right)}{2}-\frac{W_{2} \delta_{2}\left(1-\theta_{2}\right)}{\beta} \geq 0, \\
& \lim _{\eta \rightarrow 1^{-}} \frac{\partial E}{\partial \eta}<\frac{W_{1} \delta_{1}\left(1-\theta_{1}\right)}{\alpha}-\frac{W_{2} \delta_{2}\left(1-\theta_{2}\right) \beta T^{2}}{2} \leq 0 .
\end{aligned}
$$

We compute the partial derivative of Eq. (5) with respect to $\eta$ and have

$$
\begin{aligned}
\frac{\partial^{2} E(\eta)}{\partial \eta^{2}}= & -\frac{W_{2} \delta_{2}\left(1-\theta_{2}\right)}{\beta} \cdot \frac{2 e^{\beta(1-\eta) T}-[\beta T(1-\eta)]^{2}-2 \beta T(1-\eta)-2}{(1-\eta)^{3} e^{\beta(1-\eta) T}} \\
& -\frac{W_{1} \delta_{1}\left(1-\theta_{1}\right)}{\alpha} \cdot \frac{2 e^{\alpha \eta T}-(\eta \alpha T)^{2}-2 \eta \alpha T-2}{\beta^{3} e^{\alpha \eta T}}
\end{aligned}
$$


Let $f(h)=2 e^{h}-h^{2}-2 h-2(h>0)$, where $h=\{\beta T(1-\eta), \alpha T \eta\}$. We substitute $h$ into Eq. (13) and have

$$
\frac{\partial^{2} f(h)}{\partial h^{2}}=2 e^{h}-2>0
$$

Given $f(0)=0$ and the condition in Eq. (14), $f(h)$ is equal to or greater than zero. Thus

$$
\left\{\begin{array}{l}
2 e^{\alpha \eta T}-(\eta \alpha T)^{2}-2 \eta \alpha T-2>0, \\
2 e^{\beta(1-\eta) T}-[\beta T(1-\eta)]^{2}-2 \beta T(1-\eta)-2>0 .
\end{array}\right.
$$

According to Eq. (13) and Eq. (15), $\partial^{2} E(\eta) / \partial \eta^{2}<0 . \partial E(\eta) / \partial \eta$ is therefore a decreasing function of $\eta$ on the interval $(0,1)$. In other words, there exists at most one $\eta^{\otimes} \in(0,1)$ that satisfies $\partial E(\eta) /\left.\partial \eta\right|_{\eta=\eta \eta^{\otimes}}=0$. Given Eq. (11) and Eq. (12) as well as the definition of extreme value, $E(\eta)$ has and only has one extreme value, i.e., $\eta^{*}=\eta^{\otimes}$ and $E\left(\eta^{*}\right)>E(\eta), \eta \neq \eta^{*}$.

The above analysis indicates that, given the government's subsidy policy $\delta_{1} / \delta_{2}$, if the subsidy period $T$ is long enough, there must exist only one optimal decision $\eta^{*} \in(0,1)$ which makes the manufacturer's expected benefit $E(\eta)$ maximum. In other words, no matter how the government provides subsidies for the manufacturer's reserves of physical materials and production capacity, as long as the subsidy period $T$ is long, the manufacturer has an optimal decision $\eta^{*} \in(0,1)$. When the subsidy period $T$ is short, through the adjustment of $\delta_{1} / \delta_{2}$, the government can still make the manufacturer invest on the reserves of both physical materials and production capacity as an optimal decision. However, when the subsidy period $T$ is short and the subsidy policy $\delta_{1} / \delta_{2}$ is not reasonable, the manufacturer's optimal decision would be $\eta^{*}=0$ or $\eta^{*}=1$. This means that the manufacturer's optimal decision is to reserve one aspect, physical materials or production capacity, which obviously would be to the detriment of the provision of emergency supplies.

\subsection{Government's optimal decision}

The requirements of emergency supplies can be divided into two stages: beginning requirement stage and persistent requirement stage. In the beginning stage of an emergency, because the production process of goods such as tents and pharmaceuticals need time, the manufacturer mainly relies on the preserved physical materials. However, the preserved materials may not meet a durative demand. Then, the preserved production capacity could make sustaining provision of emergency supplies. Thus, provision level of emergency supplies is guaranteed through the reserves of both physical materials and production capacity. Let $z$ denote the manufacturer's provision level of supplies in case of an emergency event and $z_{0}$, being a low level, denote the initial provision level at $t=0$. We assume that the provision level in the period $T$ is related to the investment on physical materials and production capacity which is determined by investment rate $\eta$. Thus, the change of provision level over time can be written as

$$
d z / d t=z \eta^{\gamma}(1-\eta)^{1-\gamma},
$$

where $r$ is the elasticity coefficient of $\eta$. The total level of provision is the sum of provision level at each time point in the period $T$, and the total level of provision therefore can be 
written in the following integrated form:

$$
Z=\int_{0}^{T} z d t
$$

Proposition 2 If the manufacturer's optimal decision $\eta^{\oplus}$ equals $\gamma$, to make the total level of provision of emergency supplies $Z$ maximum, the government's optimal subsidy policy $\delta_{1}^{*} / \delta_{2}^{*}$ should be an increasing function of the subsidy period $T$.

Proof Given the initial provision level $z_{0}$, we solve the nonlinear differential equation (16) and obtain

$$
z=z_{0} e^{t \eta^{\gamma}(1-\eta)^{1-\gamma}} .
$$

We substitute Eq. (18) into Eq. (17) and have

$$
Z=\int_{0}^{T} z_{0} e^{t \eta^{\gamma}(1-\eta)^{1-\gamma}} d t
$$

Let $h(\eta)=\eta^{\gamma}(1-\eta)^{1-\gamma}$. We have $d^{2} h(\eta) / d \eta^{2}=\gamma(\gamma-1) \eta^{\gamma-2}(1-\eta)^{-\gamma-1}<0$. Thus, $h(\eta)$ must have a maximum value. It then follows that

$$
d h(\eta) / d \eta=\gamma \eta^{\gamma-1}(1-\eta)^{1-\gamma}-\eta^{\gamma}(1-\gamma)(1-\eta)^{-\gamma}=0 .
$$

According to Eq. (20), $\eta$ has a unique solution $\eta^{\oplus}=\gamma$ on the interval $(0,1)$, which makes $h(\eta)$ attain a maximum. If the government knows $\gamma$, it can adjust the subsidy policy $\delta_{1} / \delta_{2}$ to make the manufacturer attain the optimal decision $\eta^{\oplus}=\gamma$. Meanwhile, the total provision level of emergency supplies $Z$ also attains its maximum value. The optimal policy of the government can be obtained by substituting $\eta^{\oplus}=\gamma$ into $\partial E / \partial \eta=0$. That is,

$$
\frac{\delta_{1}^{*}}{\delta_{2}^{*}}=\frac{W_{2} \alpha\left(1-\theta_{2}\right)}{\beta W_{1}\left(1-\theta_{1}\right)} \cdot \frac{\gamma^{2}\left([(1-\gamma) \beta T+1] e^{-\beta(1-\gamma) T}-1\right)}{(1-\gamma)^{2}\left((\gamma \alpha T+1) e^{-\alpha \gamma T}-1\right)} .
$$

When the government determines $\delta_{1}^{*} / \delta_{2}^{*}$ as Eq. (21), the manufacturer can maximize its expected benefit by investing on the reserves of physical materials and production capacity in a rate of $\eta^{\oplus}$ to $1-\eta^{\oplus}$, where $\eta^{\oplus}=\gamma$.

Given $g=\delta_{1}^{*} / \delta_{2}^{*}$, we calculate the partial derivative of $g$ with respect to $T$ and obtain

$$
\begin{aligned}
\frac{\partial g}{\partial T}= & -\frac{W_{2} \alpha \gamma^{2}\left(1-\theta_{2}\right)}{W_{1} \beta(1-\gamma)^{2}\left(1-\theta_{1}\right)} \\
& \times\left(\frac{(1-\gamma)^{2} \beta^{2} T e^{-(1-\gamma) \beta T}}{(1+\gamma \alpha T) e^{-\gamma \alpha T}-1}+\frac{\left([(1-\gamma) \beta T+1] e^{-(1-\gamma) \beta T}-1\right) \gamma^{2} \alpha^{2} T e^{-\gamma \alpha T}}{\left[(1+\gamma \alpha T) e^{-\gamma \alpha T}-1\right]^{2}}\right) .
\end{aligned}
$$

If $w(h)=h e^{-h}+e^{-h}-1$, then $\partial w / \partial h=-h e^{-h}<0$ and $w(h)<w(0)=0$. It then follows that

$$
\left\{\begin{array}{l}
{[(1-\gamma) \beta T+1] e^{-(1-\gamma) \beta T}-1<0,} \\
(1+\gamma \alpha T) e^{-\gamma \alpha T}-1<0 .
\end{array}\right.
$$


Inserting Eq. (23) in Eq. (22), we find $\partial g / \partial T>0$. This means that, when the subsidy period $T$ is relatively longer, the government should place more emphasis on subsidy of physical material reserve $\left(\delta_{1}^{*}\right)$ to make the manufacturer attain its optimal decision which satisfies $\eta^{\oplus}=\gamma$, and thereby maximizing the total provision level of emergency supplies.

\section{Numerical example and simulation}

Let the manufacturer's ability in building reserves of physical materials and production capacity be $\alpha=0.8$ and $\beta=0.5$. The potential maximum of physical material and production capacity reserves are $W_{1}=3$ and $W_{2}=4$, respectively. The manufacturer's reserves of physical materials and production capacity are 1.8 and 2 when $t=0$, i.e., $\theta_{1}=0.6$ and $\theta_{2}=0.5$. The government hopes that the manufacturer would invest on reserves of both physical materials and production capacity. The government determines $\gamma=0.4$ based on past experiences. According to Eq. (8) and Eq. (9), we analyze two conditions: $\delta_{1} / \delta_{2} \leq 5 / 3$ and $\delta_{1} / \delta_{2}>5 / 3$, and use Figure 1 and Figure 2 to illustrate the relationships between $\delta_{2}$ and the subsidy period $T$ for the two conditions, with $\delta_{1}=\{0.1,0.3,0.5,0.7,0.9\}$.

As shown in Figure 1, when $\delta_{1} / \delta_{2} \leq 5 / 3$ and the subsidy period $T$ falling in the upper left region of the curves, the manufacturer will reach the optimal decision that makes its benefit maximum. When $\delta_{1} / \delta_{2}>5 / 3$ and the subsidy period $T$ falling in the lower left region of the curves, the manufacturer will also reach the optimal decision (see Figure 2). Moreover, these two ranges of $T$ can satisfy the government's demand for the strategic reserves of

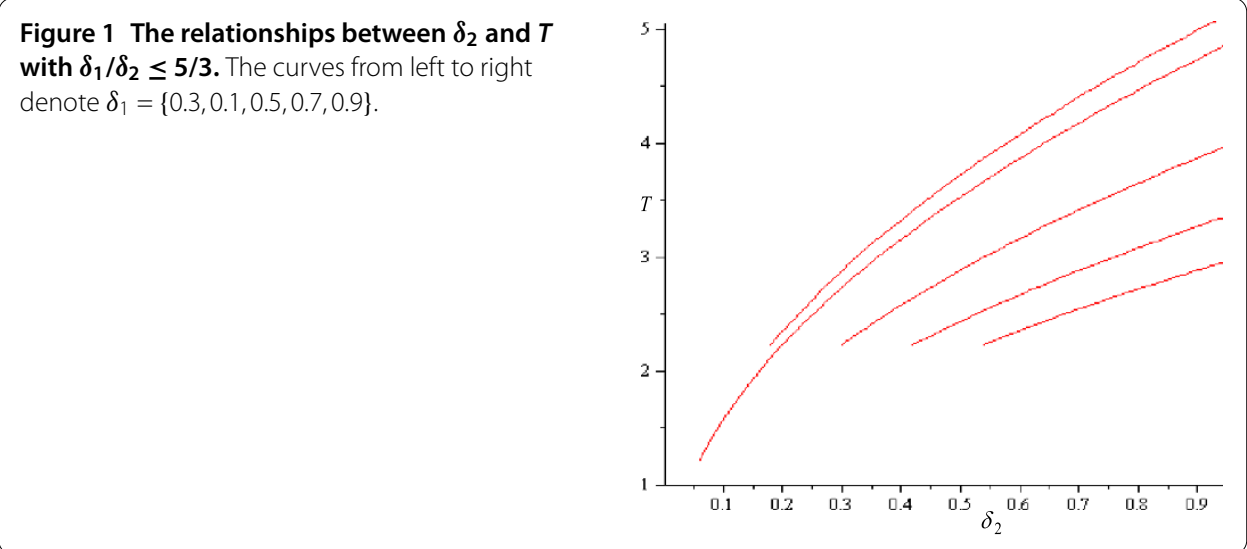

Figure 2 The relationships between $\delta_{2}$ and $T$ with $\boldsymbol{\delta}_{1} / \boldsymbol{\delta}_{\mathbf{2}}>\mathbf{5} / \mathbf{3}$. The curves from left to right denote $\delta_{1}=\{0.1,0.3,0.5,0.7,0.9\}$.

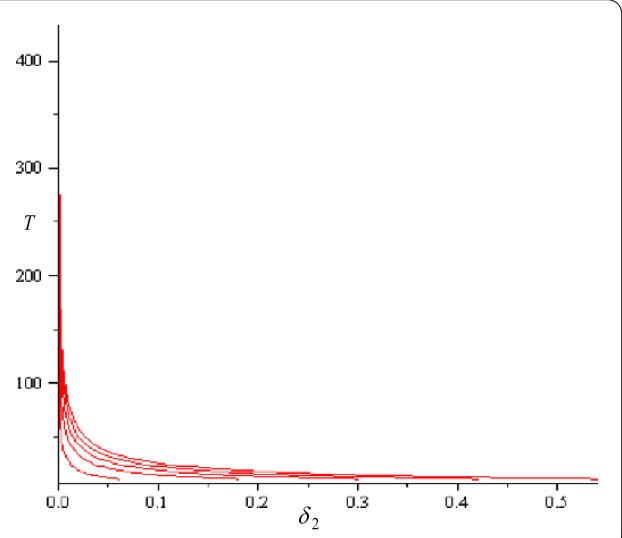



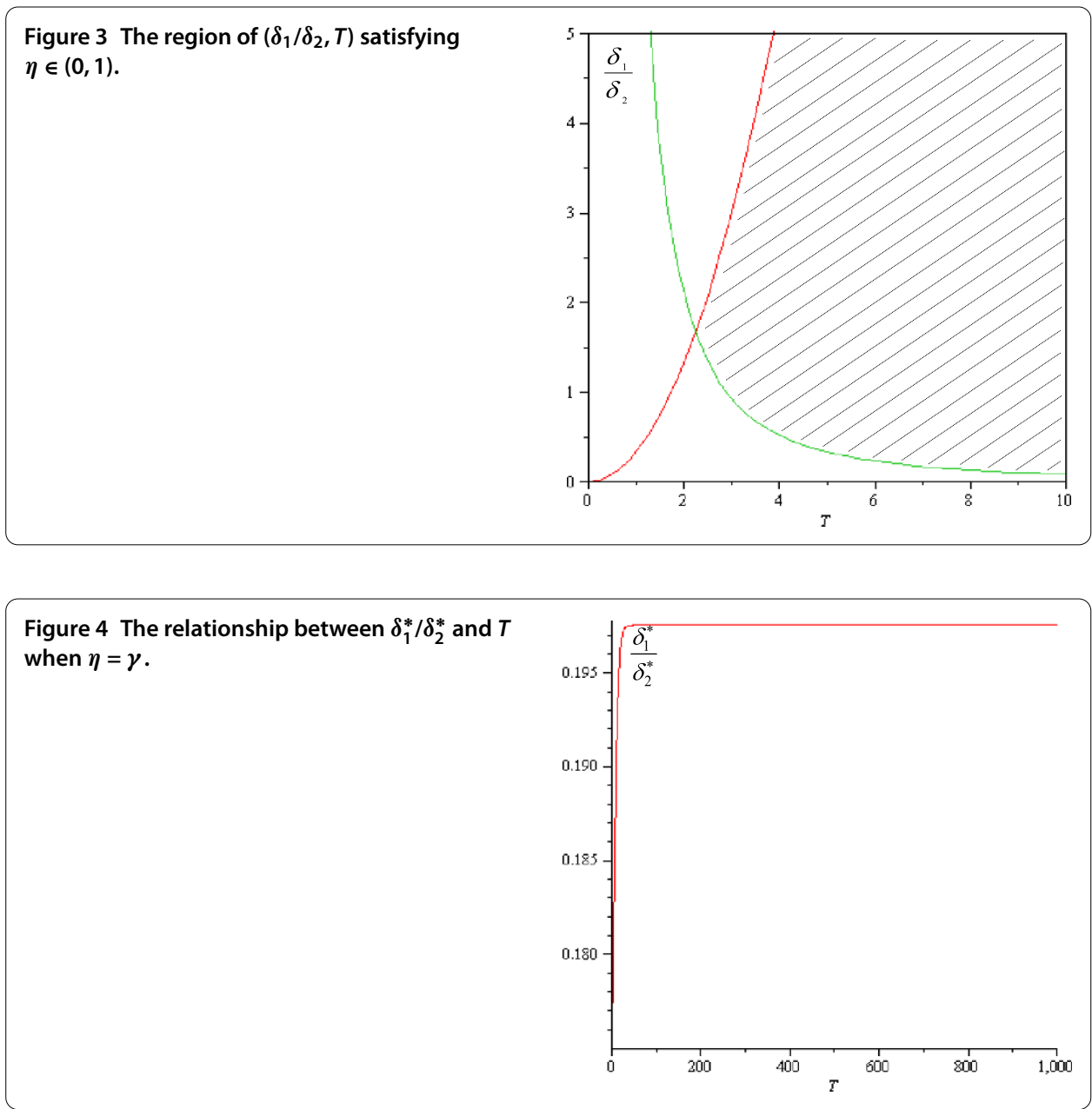

both physical materials and production capacity. That is, the manufacturer's optimal decision is not to invest on only one aspect (physical material reserve or production capacity reserve).

By substituting the values of $\alpha, \beta, W_{1}, W_{2}, \theta_{1}$, and $\theta_{2}$ into Eq. (10), we have $25 /\left(3 T^{2}\right)<$ $\delta_{1} / \delta_{2}<T^{2} / 3$ and $T>\sqrt{5}$. Figure 3 illustrates the corresponding region of $\left(\delta_{1} / \delta_{2}, T\right)$ that satisfies $\eta \in(0,1)$. As long as the government's subsidy policy $\delta_{1} / \delta_{2}$ and subsidy period $T$ simultaneously fall in the region between the two curves, it can be sure that the manufacturer will reach the optimal decision with $\eta$ on the interval $(0,1)$. According to the analysis of the government's optimal decision, when the manufacturer has taken its optimal decision $\eta=\gamma$ ( $\gamma$ is set to 0.4 in this example), the government can adjust the subsidy policy $\delta_{1} / \delta_{2}$ to obtain the highest provision level of emergency supplies. The relationships between the government's optimal subsidy policy $\delta_{1}^{*} / \delta_{2}^{*}$ and subsidy period $T$ are given in Figure 4. In other words, once the subsidy period or subsidy policy is fixed, there exists only one subsidy policy or subsidy period which attains the highest provision level of emergency supplies.

\section{Conclusion}

Catastrophic events such as natural and man-made disasters are typically characterized by a low probability of occurrence and a significant demand surge for supplies and equipment 
(Lodree Jr. and Taskin [16]). If a disaster occurs and emergency preparedness for relief materials is inadequate, then social and economic consequences can be catastrophic. Many scholars suggested that the government is obligated to seek assistances from manufactures. However, a manufacturer invests on the reserves of physical materials and production capacity based on market demand, and is often reluctant to prepare for the potential needs caused by various emergency events. Thus, it is important for the government to provide support for a manufacturer's reserves of relief materials and production capacity in case of a disaster. By formulating an incentive strategy to involve manufactures in emergency preparedness, this study extends the application of inequalities in the domain of emergency preparedness.

We found that to gain maximum benefit, the manufacturer should allocate its funds on both physical material reserve and production capacity reserve according to the government's subsidy policy, and that the government should attach importance to the relationship between subsidy policy and subsidy period to enhance the manufacturer's provision level of emergency supplies. To a large extent, successful emergency reserve relies on cooperation between the government and manufacturers. The government should encourage the manufacturers to allocate investment on extra reserves through reasonable subsidies. The mathematical models introduced in this study can make the capacities of the government and the manufacture pace in the same or in almost similar directions.

Competing interests

The authors declare that they have no competing interests.

Authors' contributions

ZZ finished the proof and the writing work. XL gave ZZ some advice on paper revision. Both authors read and approved the final manuscript.

\section{Authors' information}

Zili Zhang, Ph.D., is a lecturer at School of Management at Harbin Institute of Technology, China. Xiangyang Li is a professor at School of Management at Harbin Institute of Technology, China.

\section{Acknowledgements}

The authors would like to thank the anonymous reviewers for providing constructive comments on the earlier versions of this paper. This work is supported by the National Natural Science Foundation of China $(91024028,91024031)$.

Received: 12 October 2012 Accepted: 30 January 2013 Published: 20 February 2013

References

1. Natarajarathinam, M, Capar, I, Narayanan, A: Managing supply chains in times of crisis: a review of literature and insights. Int. J. Phys. Distrib. Logist. Manag. 39, 535-573 (2009)

2. Lettieri, E, Masella, C, Radaelli, G: Disaster management: findings from a systematic review. Disaster Prev. Manag. 18, $117-136$ (2009)

3. Wilson, J, Oyola-Yemaiel, A: The evolution of emergency management and advancement towards a profession in the United States and Florida. Saf. Sci. 39, 117-131 (2001)

4. Hense, KA, Wyler, BD, Kaufmann, G: Preparedness versus reactiveness: an approach to pre-crisis disaster planning. J. Homel. Secur. Emerg. Manag. 7, Article ID 58 (2010)

5. Edwards, FL: Recovering from Katrina: a work in progress - 2007. Public Manag. 36, 67-72 (2007/2008)

6. Johnson, BR, Connolly, E, Carter, TS: Corporate social responsibility: the role of fortune 100 companies in domestic and international natural disasters. Corp. Soc.-Responsib. Environ. Manag. 18, 352-369 (2011)

7. Stewart, GT, Kolluru, R, Smith, M: Leveraging public-private partnerships to improve community resilience in times of disaster. Int. J. Phys. Distrib. Logist. Manag. 39, 343-364 (2009)

8. Fitzgerald, ME: The emergency response plan: key to compliance with the emergency response provisions of the hazardous waste operations and emergency response standard (29 CFR 1910.120). Appl. Occup. Environ. Hyg. 11 1154-1162 (1996)

9. Cohen, MJ: State-level emergency response to the September 11 incidents: the role of New Jersey's Department of Environmental Protection. J. Conting. Crisis Manag. 11, 78-85 (2003)

10. Chen, T, Huang, J: Exploratory research on the system of China relief reserve. Syst. Eng. Proced. 5, $99-106$ (2012)

11. Hutchison, D: Lessons learned in dealing with large-scaled disasters. Insur. Risk Manag. 73, 79-88 (2005)

12. Horwitz, S: Making hurricane response more effective: lessons learned from the private sector and coast guard during Katrina. http://mercatus.org/uploadedFiles/Mercatus/Publications/PDF_20080319_ MakingHurricaneReponseEffective.pdf (2008). Accessed 28 Nov 2012 
13. Wise, CR, Nader, R: Organizing the federal system for homeland security: problems, issues, and dilemmas. Public Adm. Rev. 62, 44-57 (2002)

14. Edwards, FL: Federal intervention in local emergency planning: nightmare on main street. State Local Gov. Rev. 39, 31-43 (2007)

15. Unlu, A, Kapucu, N, Sahin, B: Disaster and crisis management in Turkey: a need for a unified crisis management system. Disaster Prev. Manag. 19, 155-174 (2010)

16. Lodree, EJ Jr., Taskin, S: An insurance risk management framework for disaster relief and supply chain disruption inventory planning. J. Oper. Res. Soc. 59, 674-684 (2008)

17. $L i, H, H e, J, Z$ hu, X: Multi-formal and information-based emergency resource reserve system in China. Chin. J. Popul. Resour. Environ. 6, 52-58 (2008)

doi:10.1186/1029-242X-2013-62

Cite this article as: Zhang and Li: The optimal manufacturer's reserve investment and government's subsidy policy in emergency preparedness. Journal of Inequalities and Applications 2013 2013:62.

Submit your manuscript to a SpringerOpen ${ }^{\circ}$ journal and benefit from:

- Convenient online submission

- Rigorous peer review

- Immediate publication on acceptance

- Open access: articles freely available online

- High visibility within the field

- Retaining the copyright to your article

Submit your next manuscript at $>$ springeropen.com 